\title{
Comparison of the morphologic criteria (RECIST) and metabolic criteria (EORTC and PERCIST) in tumor response assessments: a pooled analysis
}

\author{
Hong Deok Kim, Bum Jun Kim, Hyeong Su Kim, and Jung Han Kim
}

Division of Hemato-Oncology, Department of Internal Medicine, Hallym University Kangnam Sacred Heart Hospital, Seoul, Korea

Received: February 9, 2017

Revised : July 10, 2017

Accepted: July 19, 2017

\section{Correspondence to}

Jung Han Kim, M.D.

Division of Hemato-Oncology, Department of Internal Medicine, Hallym University Kangnam Sacred Heart Hospital, 1 Singil-ro, Yeongdeungpo-gu,

Seoul 07441, Korea

Tel: +82-2-829-5414

Fax: +82-2-846-4669

E-mail: harricil@hotmail.com
Background/Aims: The Positron Emission Tomography Response Criteria in Solid Tumors (PERCIST) or European Organization for Research and Treatment of Cancer (EORTC) criteria are used to assess metabolic tumor responses. However, tumor responses have shown considerable discrepancies between the morphologic criteria (Response Evaluation Criteria in Solid Tumors [RECIST]) and metabolic criteria. We performed this pooled study to compare the RECIST and metabolic criteria in the assessment of tumor responses.

Methods: Electronic databases were searched for eligible articles with the terms "RECIST," "PERCIST," or "EORTC criteria." The level of concordance in the tumor responses between the two criteria was estimated using $\kappa$ statistics.

Results: A total of 216 patients were collected from eight studies comparing the RECIST and EORTC criteria. The agreement of tumor responses between the two criteria was moderate $(\kappa=0.447)$. Eighty-six patients $(39.8 \%)$ showed disagreement: tumor response was upgraded in 70 patients and downgraded in 16 when adopting the EORTC criteria. The EORTC criteria significantly increased the overall response rate $(53 \%$ vs. $28 \%, p<0.0001)$. The agreement of tumor responses between the RECIST and PERCIST was deemed fair $(\kappa=0.389)$. Of 407 patients from nine studies, 181 (44.5\%) showed a discrepancy: using the PERCIST, tumor response were upgraded in 151 patients and downgraded in 30 . When adopting the PERCIST, the overall response rate was also significantly increased from $30 \%$ to $55 \%(p<0.0001)$.

Conclusions: This pooled analysis demonstrates that the concordance of tumor responses between the morphologic criteria and metabolic criteria is not excellent. When adopting the metabolic criteria instead of the RECIST, overall response rates were significantly increased.

Keywords: Response evaluation criteria in solid tumors; Positron emission tomography response criteria in solid tumors; European Organization for Research and Treatment of Cancer criteria; Tumor response

\section{INTRODUCTION}

The World Health Organization guidelines [1] and the
Response Evaluation Criteria in Solid Tumors (RECIST) $[2,3]$ are the morphologic criteria commonly used to assess tumor response in clinical practice. However, these 
criteria depending on the size changes based on computed tomography (CT) have limitations in tumors with obscure margins, cystic lesion, or scar tissue. In particular, measuring the longest diameter of lesions on CT is not always possible in gastrointestinal tumors. Because patients treated with targeted agents were not included in the data warehouse [4] when the RECIST version 1.1 was revised [3], there has also been concern regarding the assessment of tumor responses with the RECIST in patients receiving targeted agents [5]. Molecular targeted agents tend to induce necrotic or cystic change, not tumor shrinkage, in solid tumors [6]. Therefore, morphologic response criteria may be not well suited for assessing the efficacy of targeted therapies that stabilize diseases.

[18F]-fluorodeoxyglucose ([18F]-FDG) uptake is enhanced in most malignant tumors which in turn can be measured by positron emission tomography (PET). [18F]-FDG PET has been adopted as a new method for the diagnosis and staging of solid tumors. PET is also increasingly being used to monitor tumor responses to anti-cancer therapies. It can allow the assessment of tumor response even in the absence of anatomical changes [7-9]. There are two sets of criteria using FDG PET to quantify metabolic changes to anti-cancer treatment: the criteria developed by the European Organization for Research and Treatment of Cancer (EORTC) criteria [10] and the Positron Emission Tomography Response Criteria in Solid Tumors (PERCIST) [11]. Tumor response evaluations with the PERCIST and EORTC criteria have shown almost perfect agreement and correlated well with survival $[12,13]$. The metabolic response criteria may provide clinicians with a more accurate assessment of therapeutic response at an earlier stage of treatment course. However, their usefulness and advantage over the morphologic criteria (RECIST) need to be further investigated.

The assessment of tumor responses between the morphologic criteria and metabolic criteria has shown considerable discrepancies in a series of studies with a small number of patients [14-27]. We performed this pooled study to compare tumor response assessment between the morphologic criteria (RECIST 1.0 and RECIST 1.1) and metabolic criteria (EORTC criteria and PERCIST) in patients with solid tumors.

\section{METHODS}

\section{Search strategy}

A computerized systematic search of the electronic databases PubMed, Embase, Scopus, and Google Scholar (up to June 2017) was carried out to find articles with the following terms in their titles, abstracts, or keywords: "RECIST," "PERCIST," or "EORTC criteria." In addition, we checked all the references of identified relevant articles and reviews. We also used the "related articles" feature in PubMed to identify relevant articles.

\section{Study selection criteria}

Studies comparing tumor responses by using the RECIST and metabolic criteria (EORTC or PERCIST) were considered for inclusion in this pooled study. As the RECIST 1.1 showed a high concordance with the RECIST 1.0 in the assessment of tumor responses $[28,29]$, we included both versions without distinction in the analysis. For a more accurate comparison, however, articles adopting the modified RECIST versions developed for specific types of tumors were excluded. The searched articles were screened again by reviewing the full text, and the original articles that compared tumor responses between the morphologic criteria (RECIST 1.0 or RECIST 1.1) and metabolic criteria (PERCIST or EORTC) were included in the final analysis.

\section{Tumor response assessment}

The tumor responses according to the RECIST in each study were defined as follows [2,3]: (1) complete response (CR): disappearance of all lesions; (2) partial response (PR): at least a 30\% decrease in the sum of diameters of the target lesions and no new lesions; (3) progressive disease (PD): more than a $20 \%$ increase in the sum of diameters of the target lesions (and also an absolute increase of at least $5 \mathrm{~mm}$ in the RECIST 1.1) or the appearance of new lesions on CT (or PET in the RECIST 1.1); and (4) stable disease (SD): neither sufficient shrinkage to qualify as PR nor sufficient increase to qualify as PD.

The tumor response guidelines for the PERCIST and EORTC criteria are briefly summarized in Table 1.

\section{Statistics}

The overall response rate (ORR) was defined as the percentage of patients with CR or PR (as determined by the 
Table 1. Tumor response assessment by two metabolic criteria (EORTC criteria and PERCIST)

\begin{tabular}{lll}
\hline & \multicolumn{1}{c}{ EORTC } & PERCIST \\
\hline Complete metabolic response (CMR) & $\begin{array}{l}\text { Complete resolution of FDG uptake } \\
\text { in all lesions }\end{array}$ & $\begin{array}{c}\text { Complete resolution of FDG uptake in } \\
\text { all lesions }\end{array}$ \\
Partial metabolic response (PMR) & $\begin{array}{l}\geq 5 \% \text { Reduction in the sum of } \\
\text { SUVmax after more than one cycle } \\
\text { of treatment }\end{array}$ & $\begin{array}{l}\geq 30 \% \text { Reduction of the SULpeak and an } \\
\text { absolute drop of o.8 SULpeak units }\end{array}$ \\
Progressive metabolic disease (PMD) & $\begin{array}{l}\geq 5 \% \text { Increase in the sum of } \\
\text { SUVmax or appearance of new } \\
\text { FDG-avid lesions }\end{array}$ & $\begin{array}{l}\geq 30 \% \text { Increase in the SULpeak of the } \\
\text { FDG uptake and an absolute increase of } \\
\text { Stable metabolic disease (SMD) }\end{array}$ \\
\hline
\end{tabular}

EORTC, European Organization Research and Treatment of Cancer; PERCIST, Positron Emission Tomography Response Criteria in Solid Tumors; FDG, fluorodeoxyglucose; SUVmax, maximum standardized uptake value; SULpeak, peak lean body mass SUV.

two RECIST versions) and those with complete metabolic response (CMR) or partial metabolic response (PMR) (as determined by the PERCIST or EORTC criteria). The ORRs between the two groups were compared by using the McNemar test and $p$ values less than 0.05 were considered significant. The level of agreement in tumor responses between the two criteria was estimated using unweighted $\kappa$ statistics. The agreement was interpreted as poor $(\kappa<0)$, slight $(\kappa=0$ to 0.20$)$, fair $(\kappa=0.21$ to 0.40$)$, moderate ( $\kappa=0.41$ to 0.60 ), substantial ( $\kappa=0.61$ to 0.80 ), and almost perfect $(\kappa>0.80)$ [30].

\section{Ethics}

This study did not require approval by an ethics committee because it was a pooled analysis with systematic review of previously published studies. We performed this study according to the Preferred Reporting Items for Systematic Reviews and Meta-Analyses (PRISMA) guidelines [31].

\section{RESULTS}

\section{Eligible studies}

Fig. 1 shows the flowchart of studies. A total of 132 studies were identified according to the search strategy: 110 were excluded after screening the titles and abstracts. The remaining 22 articles comparing tumor responses according to the RECIST and metabolic criteria were potentially relevant. However, eight studies were excluded

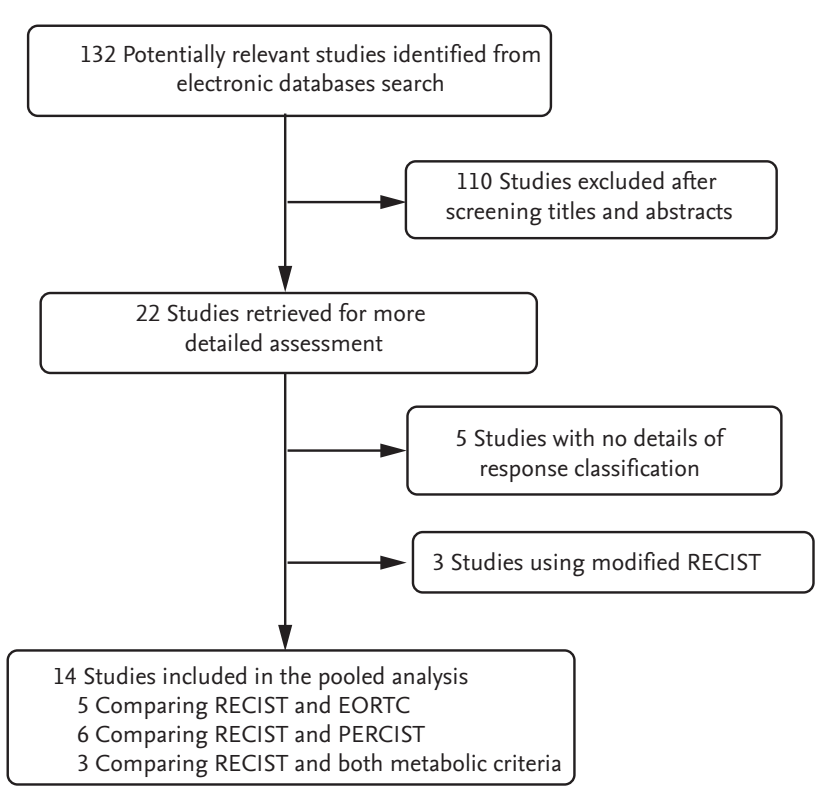

Figure 1. Flowchart of search process. RECIST, Response Evaluation Criteria in Solid Tumors; EORTC, European Organization Research and Treatment of Cancer; PERCIST, Positron Emission Tomography Response Criteria in Solid Tumors.

based on the inclusion criteria: three articles used the modified RECIST and five had no details of response classification [32-36].

Finally, 14 studies with data comparing tumor responses by the RECIST and morphologic criteria (EORTC or PERCIST) were selected [14-27]. Five articles compared the RECIST and EORTC criteria [14,16-19] and six compared the RECIST and PERCIST [22-27]. The remaining 
three studies compared the RECIST and both metabolic criteria $[15,20,21]$.

\section{Patients' characteristics}

From the eight studies comparing the RECIST and EORTC criteria [14-21], 216 patients were included; 82 with lung cancer [19-21], 45 with colorectal cancer [14,20], 33 with head and neck cancer $[18,20]$, 17 with malignant melanoma [17], 14 with basal cell carcinoma [15], 12 with stomach cancer [20], seven with desmoplastic small round cell tumors [16], and six with breast cancer [20] (Table 2). Eighty-nine patients (41.2\%) were treated with targeted agents and 127 (58.8\%) received cytotoxic chemotherapy.

From the nine studies comparing tumor responses by the RECIST and PERCIST, 407 patients were included [15,20-27]: 120 with colorectal cancer [20,23,27], 95 with lung cancer [20-22], 93 with breast cancer [20,25,26], 48 with esophageal cancer $[24,25], 14$ with basal cell carcinoma [15], 12 with stomach cancer [20], 10 with head and neck cancer [20,25], and 16 with other cancers (Table 3) [25].

\section{Comparison of tumor responses between the RE- CIST and EORTC criteria}

Because the RECIST 1.1 includes PET scans for the detection of new lesions, we reclassified tumor response of two patients with new focal FDG avid marrow lesions as PD [19]. The rate of discordance in tumor responses between the RECIST (RECIST 1.0 and RECIST 1.1) and EORTC criteria varied from $9.7 \%$ in non-small cell lung cancer [19] to 80\% in colorectal cancer [14] (Table 2). The agreement of tumor response between the two criteria was moderate $(\kappa=0.447 ; 95 \%$ confidence interval, 0.356 to 0.537 ) (Table 4). Of 216 patients, 86 (39.8\%) showed discordance in the assessment of their tumor responses between the two criteria. The details of the patients showing disagreement are described in Table 2. When adopting the EORTC criteria, tumor responses were upgraded in 70 patients and downgraded in 16. The shift in tumor responses occurred most frequently in patients with SD as determined by the RECIST. Among 68 patients with $\mathrm{SD}$, the tumor response in 56 patients (82.46\%) was upgraded to $\operatorname{CMR}(\mathrm{n}=3)$ or $\operatorname{PMR}(\mathrm{n}=53)$ and that in 12 was downgraded to progressive metabolic disease (PMD) by using the EORTC criteria. Of 10 patients with $\mathrm{PR}$, six were reclassified as showing CMR, three as having stable metabolic disease (SMD), and one as having PMD. There were eight patients with PD who were upgraded as having $\operatorname{PMR}(n=1)$ or $\operatorname{SMD}(n=7)$. As a result, the estimated ORRs, which were estimated in total regardless of the primary tumor sites, were significantly different between the two criteria $(28.2 \%$ by the RECIST vs. $52.8 \%$ by the EORTC, $p<0.0001)$.

\section{Comparison of tumor responses between the RE- CIST and PERCIST}

The rate of disagreement in tumor responses between the RECIST and PERCIST varied from 18.3\% [20] to $62.9 \%$ [25]. Of 407 patients, 181 (44.5\%) showed discordance in the assessment of their tumor responses between the two criteria. The details of the patients showing discordance are summarized in Table 3. The agreement of tumor response between the two criteria was fair ( $\kappa=0.398 ; 95 \%$ confidence interval, 0.323 to 0.456 ) (Table 5). When adopting the PERCIST, the tumor response was upgraded in 151 patients and downgraded in 30. The shift in tumor responses was also observed most frequently in patients with SD by using the RECIST. Among 120 patients with SD, the tumor response of 96 patients $(80 \%)$ was upgraded to CMR $(\mathrm{n}=11)$ or PMR (n $=85$ ) and that of 24 was downgraded to PMD by adopting the PERCIST. Of 37 patients with PR, 31 were reclassified as showing CMR and six as having SMD. There were 24 patients with $\mathrm{PD}$ who were upgraded as showing CMR $(n=4), \operatorname{PMR}(n=7)$, and SMD $(n=13)$. The estimated ORRs were also significantly different between the two criteria (30.2\% by the RECIST vs. $55.0 \%$ by the PERCIST, $p<0.0001)$.

\section{DISCUSSION}

In this pooled study, we investigated the concordance between the metabolic criteria and morphologic criteria for the assessment of tumor responses in patients with solid tumors. There was a considerable discrepancy in the assessment of tumor responses between the morphologic criteria (RECIST) and metabolic criteria (EORTC or PERCIST). When adopting the EORTC criteria or PERCIST instead of the RECIST, the ORR was significantly increased, suggesting significant clinical impact of the metabolic criteria on making therapeutic 
Table 2. Summary of eight studies comparing the RECIST and EORTC criteria

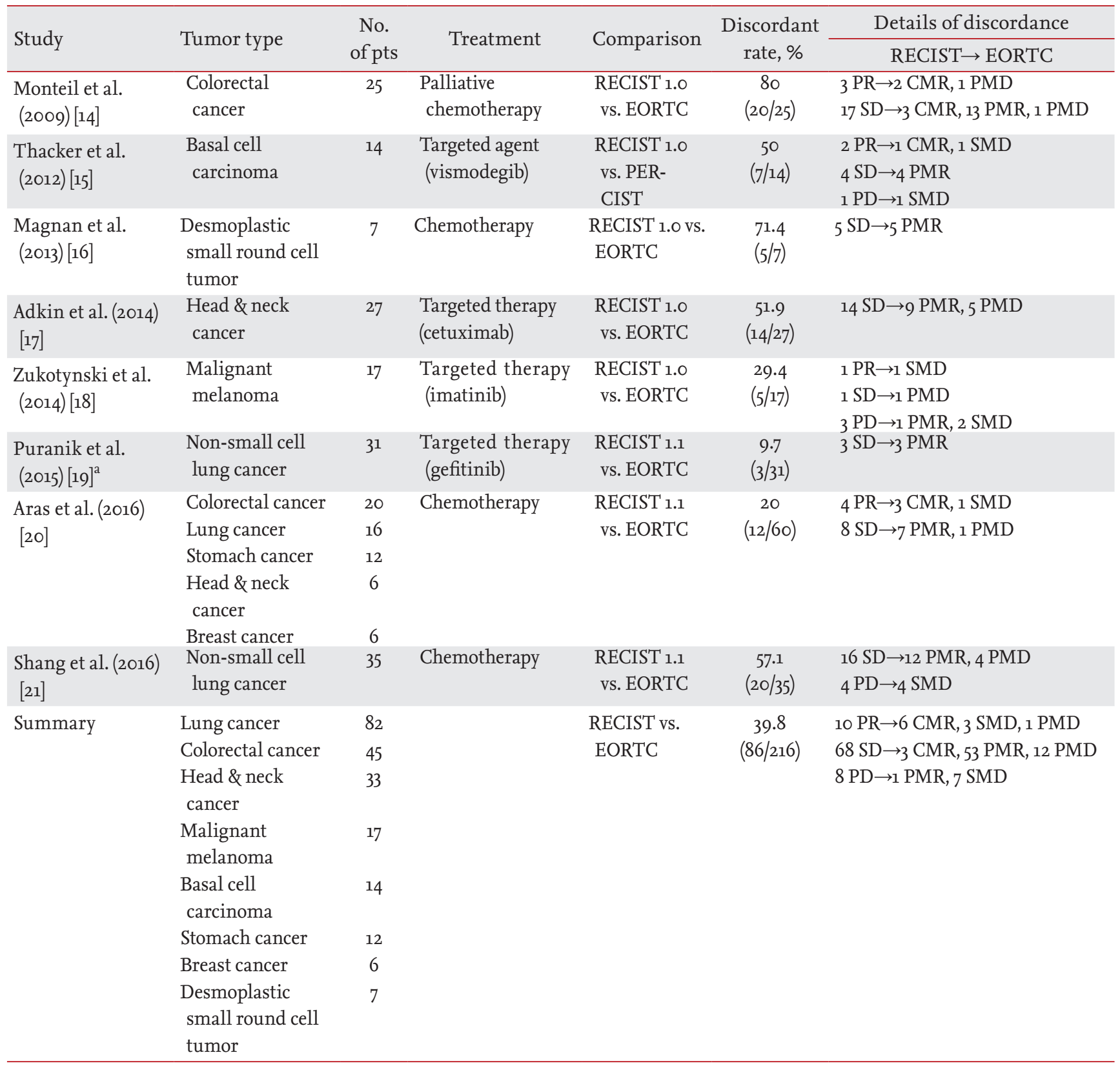

RECIST, Response Evaluation Criteria in Solid Tumors; EORTC, European Organization Research and Treatment of Cancer; pts, patients; PR, partial response; CMR, complete metabolic response; PMD, progressive metabolic disease; SD, stable disease; PMR, partial metabolic response; SMD, stable metabolic disease; PD, progressive disease.

${ }^{a}$ Because the RECIST 1.1 includes positron emission tomography for the detection of new lesions, two patients with new focal fluorodeoxyglucose avid marrow lesions were reclassified as having PD.

decision.

In clinical practice, it is not always easy to distinguish necrotic tissue or fibrotic scar from residual tumor on CT scans [37]. In particular, with the increasing use of targeted agents, new evaluation methods are needed to accurately monitor tumor responses. [18F]-FDG PET has become a well-established method for the staging and detection of recurrence in patients with several malig- 
Table 3. Summary of nine studies comparing the RECIST and PERCIST

\begin{tabular}{|c|c|c|c|c|c|c|}
\hline Study & Tumor types & $\begin{array}{l}\text { No. of } \\
\text { pts }\end{array}$ & Treatment & Comparison & $\begin{array}{l}\text { Discordant } \\
\text { rate, } \%\end{array}$ & $\begin{array}{c}\text { Details of discordance } \\
\text { RECIST } \rightarrow \text { PERCIST }\end{array}$ \\
\hline $\begin{array}{l}\text { Thacker et al. } \\
(2012)[15]\end{array}$ & $\begin{array}{l}\text { Basal cell } \\
\text { carcinoma }\end{array}$ & 14 & $\begin{array}{l}\text { Targeted agent } \\
\text { (vismodegib) }\end{array}$ & $\begin{array}{l}\text { RECIST } 1.0 \\
\text { vs. PER- } \\
\text { CIST }\end{array}$ & $\begin{array}{c}50 \\
(7 / 14)\end{array}$ & $\begin{array}{l}2 \mathrm{PR} \rightarrow 1 \mathrm{CMR}, 1 \mathrm{SMD} \\
4 \mathrm{SD} \rightarrow 4 \mathrm{PMR} \\
1 \mathrm{PD} \rightarrow 1 \mathrm{SMD}\end{array}$ \\
\hline $\begin{array}{l}\text { Aras et al. (2016) } \\
{[20]}\end{array}$ & $\begin{array}{l}\text { Colorectal cancer } \\
\text { Lung cancer } \\
\text { Stomach cancer } \\
\text { Head \& neck cancer } \\
\text { Breast cancer }\end{array}$ & $\begin{array}{r}20 \\
16 \\
12 \\
6 \\
6\end{array}$ & $\begin{array}{l}\text { Palliative } \\
\text { chemotherapy }\end{array}$ & $\begin{array}{l}\text { RECIST } 1.1 \\
\text { vs. PER- } \\
\text { CIST }\end{array}$ & $\begin{array}{c}18.3 \\
(11 / 60)\end{array}$ & $\begin{array}{l}4 \mathrm{PR} \rightarrow 3 \mathrm{CMR}, 1 \mathrm{SMD} \\
7 \mathrm{SD} \rightarrow 7 \mathrm{PMR}\end{array}$ \\
\hline $\begin{array}{l}\text { Shang et al. } \\
(2016)[21]\end{array}$ & $\begin{array}{l}\text { Non-small cell lung } \\
\text { cancer }\end{array}$ & 35 & Chemotherapy & $\begin{array}{l}\text { RECIST } 1.1 \\
\text { vs. PER- } \\
\text { CIST }\end{array}$ & $\begin{array}{c}62.9 \\
(22 / 35)\end{array}$ & $\begin{array}{l}18 \mathrm{SD} \rightarrow 14 \mathrm{PMR}, 4 \mathrm{PMD} \\
4 \mathrm{PD} \rightarrow 4 \mathrm{SMD}\end{array}$ \\
\hline $\begin{array}{l}\text { Ding et al. (2014) } \\
{[22]}\end{array}$ & $\begin{array}{l}\text { Non-small cell } \\
\text { lung cancer }\end{array}$ & 44 & $\begin{array}{l}\text { Palliative } \\
\text { chemotherapy }\end{array}$ & $\begin{array}{l}\text { RECIST } 1.1 \\
\text { vs. PER- } \\
\text { CIST }\end{array}$ & $\begin{array}{c}34.1 \\
(15 / 44)\end{array}$ & $\begin{array}{l}6 \mathrm{PR} \rightarrow 4 \mathrm{CMR}, 2 \mathrm{SMD} \\
9 \mathrm{SD} \rightarrow 1 \mathrm{CMR}, 7 \mathrm{PMR}, 1 \mathrm{PMD}\end{array}$ \\
\hline $\begin{array}{l}\text { Skougaard et al. } \\
(2014)[23]\end{array}$ & $\begin{array}{l}\text { Colorectal } \\
\text { cancer }\end{array}$ & 61 & $\begin{array}{l}\text { Palliative } \\
\text { chemotherapy }\end{array}$ & $\begin{array}{l}\text { RECIST } 1.0 \\
\text { vs. PER- } \\
\text { CIST }\end{array}$ & $\begin{array}{c}54.1 \\
(33 / 61)\end{array}$ & $\begin{array}{l}1 \mathrm{PR} \rightarrow 1 \mathrm{SMD} \\
24 \mathrm{SD} \rightarrow 20 \mathrm{PMR}, 4 \mathrm{PMD} \\
8 \mathrm{PD} \rightarrow 4 \mathrm{PMR}, 4 \mathrm{SMD}\end{array}$ \\
\hline $\begin{array}{l}\text { Yanagawa et al. } \\
(2012)[24]^{\mathrm{a}}\end{array}$ & $\begin{array}{l}\text { Esophageal } \\
\text { cancer }\end{array}$ & 46 & $\begin{array}{l}\text { Neoadjuvant } \\
\text { chemotherapy }\end{array}$ & $\begin{array}{l}\text { RECIST } 1.1 \\
\text { vs. PER- } \\
\text { CIST }\end{array}$ & $\begin{array}{c}56.5 \\
(26 / 46)\end{array}$ & $\begin{array}{l}{ }_{13} \mathrm{PR} \rightarrow 13 \mathrm{CMR} \\
13 \mathrm{SD} \rightarrow 3 \mathrm{CMR}, 10 \mathrm{PMR}\end{array}$ \\
\hline $\begin{array}{l}\text { Agrawal et al. } \\
(2014)[25]\end{array}$ & $\begin{array}{l}\text { Breast cancer } \\
\text { PNET } \\
\text { Head \& neck cancer } \\
\text { Sarcoma } \\
\text { NHL } \\
\text { Esophageal cancer } \\
\text { Others }\end{array}$ & $\begin{array}{r}22 \\
5 \\
4 \\
3 \\
2 \\
2 \\
5\end{array}$ & $\begin{array}{l}\text { Metronomic } \\
\text { palliative } \\
\text { hemotherapy }\end{array}$ & $\begin{array}{l}\text { RECIST } 1.1 \\
\text { vs. PER- } \\
\text { CIST }\end{array}$ & $\begin{array}{l}20.6 \\
(9 / 43)\end{array}$ & $\begin{array}{l}8 \mathrm{SD} \rightarrow 1 \mathrm{CMR}, 1 \mathrm{PMR}, 6 \mathrm{PMD} \\
1 \mathrm{PD} \rightarrow 1 \mathrm{CMR}\end{array}$ \\
\hline $\begin{array}{l}\text { Riedl et al. (2017) } \\
{[26]}\end{array}$ & Breast cancer & 65 & $\begin{array}{l}\text { Chemotherapy, } \\
\text { targeted } \\
\text { therapy, } \\
\text { hormonal } \\
\text { therapy }\end{array}$ & $\begin{array}{l}\text { RECIST } 1.1 \\
\text { vs. } \\
\text { PERCIST }\end{array}$ & $\begin{array}{c}52.3 \\
(34 / 65)\end{array}$ & $\begin{array}{l}10 \mathrm{PR} \rightarrow 10 \mathrm{CMR} \\
20 \mathrm{SD} \rightarrow 6 \mathrm{CMR}, 8 \mathrm{PMR}, 6 \mathrm{PMD} \\
4 \mathrm{PD} \rightarrow 3 \mathrm{CMR}, 1 \mathrm{SMD}\end{array}$ \\
\hline $\begin{array}{l}\text { Bang et al. (2017) } \\
{[27]}\end{array}$ & Colorectal cancer & 39 & $\begin{array}{l}\text { Targeted therapy } \\
\text { (regorafenib) }\end{array}$ & $\begin{array}{l}\text { RECIST } 1.1 \\
\text { vs. } \\
\text { PERCIST }\end{array}$ & $\begin{array}{c}61.5 \\
(24 / 39)\end{array}$ & $\begin{array}{l}1 \mathrm{PR} \rightarrow 1 \mathrm{SMD} \\
17 \mathrm{SD} \rightarrow 14 \mathrm{PMR}, 3 \mathrm{PMD} \\
6 \mathrm{PD} \rightarrow 3 \mathrm{PMR}, 3 \mathrm{SMD}\end{array}$ \\
\hline Summary & $\begin{array}{l}\text { Colorectal cancer } \\
\text { Lung cancer } \\
\text { Breast cancer } \\
\text { Esophageal cancer } \\
\text { Basal cell } \\
\text { carcinoma } \\
\text { Stomach cancer } \\
\text { Head \& neck cancer } \\
\text { Others }\end{array}$ & $\begin{array}{r}120 \\
95 \\
93 \\
48 \\
14 \\
12 \\
10 \\
16\end{array}$ & & $\begin{array}{l}\text { RECIST vs. } \\
\text { PERCIST }\end{array}$ & $\begin{array}{c}44 \cdot 5 \\
(181 / 407)\end{array}$ & $\begin{array}{l}37 \mathrm{PR} \rightarrow 31 \mathrm{CMR}, 6 \mathrm{SMD} \\
120 \mathrm{SD} \rightarrow 11 \mathrm{CMR}, 85 \mathrm{PMR} \text {, } \\
24 \mathrm{PMD} \\
24 \mathrm{PD} \rightarrow 4 \mathrm{CMR}, 7 \mathrm{PMR}, \\
13 \mathrm{SMD}\end{array}$ \\
\hline
\end{tabular}

RECIST, Response Evaluation Criteria in Solid Tumors; PERCIST, Positron Emission Tomography Response Criteria in Solid Tumors; pts, patients; PR, partial response; CMR, complete metabolic response; SMD, stable metabolic disease; SD, stable disease; PMR, partial metabolic response; PD, progressive disease; PMD, progressive metabolic disease; PNET, primitive neuroectodermal tumor; NHL, non-Hodgkin's lymphoma.

${ }^{a}$ Five patients were excluded from the final analysis because their disease was not classifiable according to the RECIST 1.1. 
Table 4. Comparison of tumor responses according to the RECIST and EORTC criteria

\begin{tabular}{|c|c|c|c|c|c|}
\hline \multirow{2}{*}{ Tumor response by the RECIST } & \multicolumn{4}{|c|}{ Tumor response by the EORTC } & \multirow{2}{*}{ Total } \\
\hline & CMR & PMR & SMD & PMD & \\
\hline CR & 5 & 0 & 0 & 0 & 5 \\
\hline PR & 6 & 46 & 3 & 1 & 56 \\
\hline $\mathrm{SD}$ & 3 & 53 & 25 & 12 & 93 \\
\hline $\mathrm{PD}$ & 0 & 1 & 7 & 54 & 62 \\
\hline Total & 14 & 100 & 35 & 67 & 216 \\
\hline
\end{tabular}

The level of concordance of tumor responses between the EORTC criteria and RECIST is 0.447 (unweighted $\kappa, 95 \%$ confidence interval, 0.356 to 0.537 ). The overall response rates were significantly different between the two criteria (28.2\% by RECIST vs. $52.8 \%$ by EORTC, $p<0.0001)$.

RECIST, Response Evaluation Criteria in Solid Tumors; EORTC, European Organization Research and Treatment of Cancer; CMR, complete metabolic response; PMR, partial metabolic response; SMD, stable metabolic disease; PMD, progressive metabolic disease; CR, complete response; PR, partial response; SD, stable disease; PD, progressive disease.

nancies [38]. It is also increasingly used to assess tumor responses to anti-cancer therapies [8-10]. FDG PET responses have correlated more significantly with survival than those assessed by CT [39]. However, the metabolic response criteria have shown differences compared with the morphologic criteria for the assessment of tumor responses.

In our pooled analysis of 216 patients from eight studies [14-21], the agreement of tumor responses between the RECIST and EORTC criteria was moderate $(\kappa=$ 0.447). Eighty-six patients (39.8\%) showed discrepancies in the assessment of tumor responses between the two criteria. Use of the EORTC criteria resulted in upgraded tumor responses in 70 patients and downgraded responses in 16. When adopting the EORTC criteria, the ORR significantly increased from $28.2 \%$ to $52.8 \%$ ( $p<$ 0.0001). The agreement of tumor responses between the RECIST and PERCIST was deemed fair $(\kappa=0.389)$. Of 407 patients from nine studies [15,20-27], 181 (44.5\%) showed a disagreement in tumor responses between the two criteria. Use of the PERCIST resulted in upgraded tumor responses in 151 patients and downgraded responses in 30. When adopting the PERCIST instead of the RECIST, the ORR also significantly increased from $30.2 \%$ to $55.0 \%$ ( $p<0.0001)$.

Early detection of the tumor response is of great value to avoid unnecessary toxicity and cost of ineffective treatments. Anatomical responses based on the size of the tumor may lag weeks or months behind metabolic response [40]. PET can detect metabolic changes af- ter chemotherapy even when there are no or minimal morphological changes [7], which may explain the reason why tumor responses were upgraded by using the metabolic criteria in many patients who showed SD by using the RECIST in this study. In clinical practice, patients showing disease progression (PD or PMD) after anti-cancer treatment usually need a change in therapeutic approach. If the metabolic criteria had been used instead of the RECIST in this pooled study, it would have changed the treatment course in approximately $10 \%$ of the patients. This finding indicates that the clinical impact of the metabolic response criteria on making therapeutic decisions is significant.

The current pooled study has several inherent limitations. First, this study included heterogeneous patients with different types of tumors and different kinds of therapeutic agents. In addition, because of the limited number of studies, we could not compare two criteria in the subgroup with the same cancers. It is necessary to verify these results in studies with larger homogeneous patients' cohort. Second, we included two versions of the RECIST without distinction in the analysis. Although the RECIST 1.1 has shown almost perfect agreement with the RECIST 1.0 in the assessment of tumor responses, a potential difference between the two versions might affect the results. Finally, this study could not evaluate the prognostic value of the metabolic criteria. Although the PERCIST and EORTC criteria were associated with prognosis in several studies, survival data were not enough to compare the prognostic value 
Table 5. Comparison of tumor responses according to the RECIST and PERCIST

\begin{tabular}{|c|c|c|c|c|c|}
\hline \multirow{2}{*}{ Tumor response by RECIST } & \multicolumn{4}{|c|}{ Tumor response by PERCIST } & \multirow{2}{*}{ Total } \\
\hline & CMR & PMR & SMD & PMD & \\
\hline CR & 8 & 0 & 0 & 0 & 8 \\
\hline PR & 31 & 78 & 6 & o & 115 \\
\hline $\mathrm{SD}$ & 11 & 85 & 60 & 24 & 180 \\
\hline $\mathrm{PD}$ & 4 & 7 & 13 & 80 & 104 \\
\hline Total & 54 & 170 & 79 & 104 & 407 \\
\hline
\end{tabular}

The level of concordance of tumor responses between the RECIST and PERCIST 1.0 is 0.389 (unweighted $\kappa$, with $95 \%$ confidence interval, 0.323 to 0.456 ). The overall response rates were significantly different between two criteria (30.2\% by RECIST vs. $55.0 \%$ by PERCIST, $p<0.0001$ ).

RECIST, Response Evaluation Criteria in Solid Tumors; PERCIST, Positron Emission Tomography Response Criteria in Solid Tumors; CMR, complete metabolic response; PMR, partial metabolic response; SMD, stable metabolic disease; PMD, progressive metabolic disease; CR, complete response; PR, partial response; $\mathrm{SD}$, stable disease; PD, progressive disease.

between the RECIST and the metabolic criteria.

In conclusion, this pooled study demonstrates that concordance in the assessment of tumor responses between the morphologic criteria (RECIST) and metabolic criteria (EORTC or PERCIST) is not excellent. When adopting the metabolic criteria instead of the RECIST, the ORR was significantly increased. The prognostic value of the metabolic criteria needs to be investigated in larger studies with homogeneous patient cohorts.

\section{KEY MESSAGE}

1. The assessment of tumor responses between the morphologic criteria and metabolic criteria has shown considerable discrepancies in studies with a small sample size.

2. The agreement of tumor responses was moderate between the morphologic (Response Evaluation Criteria in Solid Tumors [RECIST]) and metabolic criteria (European Organization for Research and Treatment of Cancer or Positron Emission Tomography Response Criteria in Solid Tumors).

3. When adopting the metabolic criteria instead of the RECIST, the overall response rate was significantly increased.

\section{Conflict of interest}

No potential conflict of interest relevant to this article was reported.

\section{REFERENCES}

1. Miller AB, Hoogstraten B, Staquet M, Winkler A. Reporting results of cancer treatment. Cancer 1981;47:207-214.

2. Therasse P, Arbuck SG, Eisenhauer EA, et al. New guidelines to evaluate the response to treatment in solid tumors. European Organization for Research and Treatment of Cancer, National Cancer Institute of the United States, National Cancer Institute of Canada. J Natl Cancer Inst 2000;92:205-216.

3. Eisenhauer EA, Therasse P, Bogaerts J, et al. New response evaluation criteria in solid tumours: revised RECIST guideline (version 1.1). Eur J Cancer 2009;45:228-247.

4. Bogaerts J, Ford R, Sargent D, et al. Individual patient data analysis to assess modifications to the RECIST criteria. Eur J Cancer 2009;45:248-260.

5. Liu Y, Litiere S, de Vries EG, et al. The role of response evaluation criteria in solid tumour in anticancer treatment evaluation: results of a survey in the oncology community. Eur J Cancer 2014;50:260-266.

6. Shankar LK, Van den Abbeele A, Yap J, Benjamin R, Scheutze S, Fitzgerald TJ. Considerations for the use of imaging tools for phase II treatment trials in oncology. Clin Cancer Res 2009;15:1891-1897.

7. Krystal GW, Alesi E, Tatum JL. Early FDG/PET scanning 
as a pharmacodynamics marker of anti-EGFR antibody activity in colorectal cancer. Mol Cancer Ther 2012;11:13851388.

8. Skoura E, Datseris IE, Platis I, Oikonomopoulos G, Syrigos $\mathrm{KN}$. Role of positron emission tomography in the early prediction of response to chemotherapy in patients with non-small-cell lung cancer. Clin Lung Cancer 2012;13:181-187.

9. Lee DH, Kim SK, Lee HY, et al. Early prediction of response to first-line therapy using integrated 18F-FDG PET/CT for patients with advanced/metastatic non-small cell lung cancer. J Thorac Oncol 2009;4:816-821.

10. Young H, Baum R, Cremerius U, et al. Measurement of clinical and subclinical tumour response using [18F]-fluorodeoxyglucose and positron emission tomography: review and 1999 EORTC recommendations. European Organization for Research and Treatment of Cancer (EORTC) PET Study Group. Eur J Cancer 1999;35:1773-1782.

11. Wahl RL, Jacene H, Kasamon Y, Lodge MA. From RECIST to PERCIST: evolving considerations for PET response criteria in solid tumors. J Nucl Med 2009;50 Suppl 1:122S-150S.

12. Kim JH. Comparison of the EORTC criteria and PERCIST in solid tumors: a pooled analysis and review. Oncotarget 2016;7:58105-58110.

13. Skougaard K, Nielsen D, Jensen BV, Hendel HW. Comparison of EORTC criteria and PERCIST for PET/CT response evaluation of patients with metastatic colorectal cancer treated with irinotecan and cetuximab. J Nucl Med 2013;54:1026-1031.

14. Monteil J, Mahmoudi N, Leobon S, et al. Chemotherapy response evaluation in metastatic colorectal cancer with FDG PET/CT and CT scans. Anticancer Res 2009;29:25632568.

15. Thacker CA, Weiss GJ, Tibes R, et al. 18-FDG PET/CT assessment of basal cell carcinoma with vismodegib. Cancer Med 2012;1:230-236.

16. Magnan H, Abramson SJ, Price AP, et al. Positron emission tomography for response assessment in desmoplastic small round cell tumor. J Pediatr Hematol Oncol 2013;35:e19o-e193.

17. Adkins D, Ley J, Dehdashti F, et al. A prospective trial comparing FDG-PET/CT and CT to assess tumor response to cetuximab in patients with incurable squamous cell carcinoma of the head and neck. Cancer Med 2014;3:1493-1501.
18. Zukotynski K, Yap JT, Giobbie-Hurder A, et al. Metabolic response by FDG-PET to imatinib correlates with exon 11 KIT mutation and predicts outcome in patients with mucosal melanoma. Cancer Imaging 2014;14:30.

19. Puranik AD, Purandare NC, Shah S, Agrawal A, Rangarajan V. Role of FDG PET/CT in assessing response to targeted therapy in metastatic lung cancers: morphological versus metabolic criteria. Indian J Nucl Med 2015;30:21-25.

20. Aras M, Erdil TY, Dane F, et al. Comparison of WHO, RECIST 1.1, EORTC, and PERCIST criteria in the evaluation of treatment response in malignant solid tumors. Nucl Med Commun 2016;37:9-15.

21. Shang J, Ling X, Zhang L, et al. Comparison of RECIST, EORTC criteria and PERCIST for evaluation of early response to chemotherapy in patients with non-small-cell lung cancer. Eur J Nucl Med Mol Imaging 2016;43:19451953.

22. Ding Q, Cheng X, Yang L, et al. PET/CT evaluation of response to chemotherapy in non-small cell lung cancer: PET response criteria in solid tumors (PERCIST) versus response evaluation criteria in solid tumors (RECIST). J Thorac Dis 2014;6:677-683.

23. Skougaard K, Johannesen $\mathrm{HH}$, Nielsen D, et al. CT versus FDG-PET/CT response evaluation in patients with metastatic colorectal cancer treated with irinotecan and cetuximab. Cancer Med 2014;3:1294-1301.

24. Yanagawa M, Tatsumi M, Miyata H, et al. Evaluation of response to neoadjuvant chemotherapy for esophageal cancer: PET response criteria in solid tumors versus response evaluation criteria in solid tumors. J Nucl Med 2012;53:872-88o.

25. Agrawal A, Purandare N, Shah S, Puranik A, Banavali $\mathrm{S}$, Rangarajan V. Response assessment in metronomic chemotherapy: RECIST or PERCIST? Indian J Nucl Med 2014;29:74-80.

26. Riedl CC, Pinker K, Ulaner GA, et al. Comparison of FDG-PET/CT and contrast-enhanced CT for monitoring therapy response in patients with metastatic breast cancer. Eur J Nucl Med Mol Imaging 2017;44:1428-1437.

27. Bang JI, Lim Y, Paeng JC, et al. Comparison of quantitative methods on FDG PET/CT for treatment response evaluation of metastatic colorectal cancer. Nucl Med Mol Imaging 2017;51:147-153.

28. Kim JH, Min SJ, Jang HJ, Cho JW, Kim SH, Kim HS. Comparison of RECIST 1.0 and RECIST 1.1 in patients with metastatic cancer: a pooled analysis. J Cancer 
2015;6:387-393.

29. Kim JH. Comparison of the RECIST 1.0 and RECIST 1.1 in patients treated with targeted agents: a pooled analysis and review. Oncotarget 2016;7:13680-13687.

30. Roberts C. Modelling patterns of agreement for nominal scales. Stat Med 2008;27:810-830.

31. Liberati A, Altman DG, Tetzlaff J, et al. The PRISMA statement for reporting systematic reviews and meta-analyses of studies that evaluate healthcare interventions: explanation and elaboration. BMJ 2009;339:b270o.

32. Borksuz MF, Erselcan T, Hasbek Z, Yucel B, Turgut B. Morphologic and metabolic comparison of treatment responsiveness with 18fludeoxyglucose-positron emission tomography/computed tomography according to lung cancer type. Mol Imaging Radionucl Ther 2016;25:63-69.

33. Ozturk H. Comparing RECIST with EORTC criteria in metastatic bladder cancer. J Cancer Res Clin Oncol 2016;142:187-194.

34. Mertens LS, Fioole-Bruining A, van Rhijn BW, et al. FDG-positron emission tomography/computerized tomography for monitoring the response of pelvic lymph node metastasis to neoadjuvant chemotherapy for bladder cancer. J Urol 2013;189:1687-1691.
35. Ordu C, Selcuk NA, Akosman C, et al. Comparison of metabolic and anatomic response to chemotherapy based on PERCIST and RECIST in patients with advanced stage non-small cell lung cancer. Asian Pac J Cancer Prev 2015;16:321-326.

36. Stefano A, Russo G, Ippolito M, et al. Evaluation of erlotinib treatment response in non-small cell lung cancer using metabolic and anatomic criteria. Q J Nucl Med Mol Imaging 2016;60:264-273.

37. Suzuki C, Jacobsson H, Hatschek T, et al. Radiologic measurements of tumor response to treatment: practical approaches and limitations. Radiographics 2008;28:329-344.

38. Fletcher JW, Djulbegovic B, Soares HP, et al. Recommendations on the use of 18F-FDG PET in oncology. J Nucl Med 2008;49:480-508.

39. Mac Manus MP, Hicks RJ, Matthews JP, et al. Positron emission tomography is superior to computed tomography scanning for response-assessment after radical radiotherapy or chemoradiotherapy in patients with nonsmall-cell lung cancer. J Clin Oncol 2003;21:1285-1292.

40. Van den Abbeele AD. The lessons of GIST-PET and PET/ CT: a new paradigm for imaging. Oncologist 2008;13 Suppl 2:8-13. 